\title{
Electromagnetic heating for industrial kilning of malt- a feasibility study
}

R.S. Ferrari-Johna, J. Katriba, E. Zervaa,b, N. Davies ${ }^{c}$, D.J. Cook ${ }^{b}$, C. Doddsa , S. Kingman ${ }^{a}$

a Department of Chemical and Environmental Engineering, The University of Nottingham, University Park, Nottingham, NG7 2RD, United Kingdom

${ }^{b}$ Division of Food Sciences, The University of Nottingham, Sutton Bonington Campus, Loughborough, LE12 5RD, United Kingdom

c Muntons, Cedars Maltings, Stowmarket, IP14 2AG, United Kingdom

* Corresponding author. Tel.: +44 (0)115 951 4080; fax: +44 (0)115 951 4115. E-mail address: becca.john@nottingham.ac.uk (R.S. Ferrari-John)

\section{Keywords}

microwave, radio frequency, malt, kilning

\begin{abstract}
Industrial malting operations use $\sim 800 \mathrm{kWh} / \mathrm{t}$ of energy to produce the heat required to kiln malt. Electromagnetic heating technologies are suggested as a way to potentially improve the energy efficiency of the kilning processing. In this work, the potential for using electromagnetic heating to dry malt to commercially acceptable moisture levels, whilst preserving the activity of enzymes critical for downstream brewing processes is investigated. The $2450 \mathrm{MHz}$ bulk dielectric properties of malt at moisture contents consistent with those occurring at different points in the kilning process are evaluated; $12 \%$ is shown to be a critical moisture level below which drying becomes more energy intensive. Calculated penetration depths of electromagnetic energy in malt at radio frequency are 100 fold higher than at microwave frequencies, showing a significant advantage for commercial scale batch processing. The moisture contents and alpha and beta amylase activity of malt subjected to RF heating at different temperatures, treatment times and RF energy inputs in the intermediate and bound water drying regions were determined. It is shown for the first time that whilst significantly reduced process times are attainable, significant energy efficiency improvements compared to conventional kilning can only be achieved at higher product temperatures and thus at the expense of enzyme survival. It is suggested that RF heating may be feasible where higher bulk temperatures are not critical for downstream use of the material or when used in hybrid systems.
\end{abstract}


Introduction

By 2030, it is predicted that global population growth will increase food production demands by $50 \%$ and energy demands by $45 \%$ (Beddington 2009). Consequently, food and energy security is high on the agenda of many governments (Tassou et al. 2014). The UK Government's Climate Change Agreements (CCA) scheme has been implemented to provide discounts on the Climate Change Levy (CCL) for energy intensive industries that meet targets for reduced energy use and $\mathrm{CO}_{2}$ emissions.

The UK malting sector has targeted a 4.7\% improvement in energy efficiency by 2020 (DEFRA 2013). This is in addition to a $12 \%$ target saving from 1999 to 2010 . UK maltsters currently consume some 1375 GWh of secondary energy a year in the production of around 1.5 million tonnes of malt; at least $78 \%$ of this energy is used to provide heat for the evaporation of water in the kilning process (CarbonTrust 2011). A number of steps for improving energy efficiency within the malting process have been identified, from the implementation of best practice such as combined heat and power (CHP), to innovations such as novel drying technologies.

A driver for commercial uptake of new technologies is the provision of a techno-economic advantage within a competitive market (Betz 2003). Microwave heating has been proposed as a potential new technology that could be incorporated into the malt drying process to increase energy efficiency and therefore reduce energy costs. The possible benefits of microwave processing arise from selective heating of specific phases (in this case water) within the bulk material and the ability to dissipate energy throughout the body of the material, leading to potentially faster processing times compared to conventional heating. This can lead to reduced plant footprint, energy savings and greater process control (Jones et al. 2002). Hundreds of papers are published annually on the use of electromagnetic energy to process materials, yet very few applications reach industrial scale (Buttress et al. 2015). Aside from early understanding of the techno-economic benefits, fundamental understanding of the electromagnetic-material interactions, and how this varies throughout the process, is key to successful design and scale up, yet is often lacking in many feasibility studies.

The microwave-material interactions (dielectric properties) of numerous particulate materials, including agricultural products, have been reported in the literature, mainly for application to grain moisture measurement and stored grain insect disinfestation (Nelson 2008). Whilst the literature provides an important basis for predicting material interactions at different frequencies, temperatures and bulk densities (Nelson and Trabelsi 2006; Trabelsi and Nelson 2003; Trabelsi et al. 2001; Trabelsi and Nelson 2006; Trabelsi and Nelson 2007) previous studies do not address how these properties vary under process conditions. During kilning, green malt must be dried from around $46 \%$ moisture down to approximately $2-4 \%$ to yield a product that is stable during storage and amenable to milling (Whitehurst and Van Oort 2010; CarbonTrust 2011). Kilning is separated into three physical stages: removal of free water (down to $25 \%$ moisture) intermediate stage (25-12\% moisture) and removal of bound water (below 12\%)(Briggs et al. 1981). The 
critical fundamental understanding required for applying dielectric heating to the malt kilning process is how the moisture content and degree of moisture binding in steeped and germinated barley grains influences the dielectric properties and resulting penetration depth. The penetration depth of electromagnetic energy into a material is a function of both the dielectric properties and the frequency; this is a key parameter when designing and scaling up dielectric heating processes.

The principal objective of malting is to encourage the germinating barley to produce the enzymes required to break down starch into sugars in downstream brewing processes (O'Rourke 2002). During the kilning process, these enzymes must be stabilised and preserved (Whitehurst and Van Oort 2010). Of the two principal diastatic enzymes in malt, alpha amylase is denatured above $65^{\circ} \mathrm{C}$ and beta amylase from $55^{\circ} \mathrm{C}$. The effects of both time and temperature on these enzymes are well characterised for kilning using conventional hot air drying (Kunze et al. 1999). However there have been no studies quantifying the activity of enzymes under selective dielectric heating.

The aim of this study is to determine the technical feasibility of replacing hot air drying with selective dielectric based kilning of malt. Bulk dielectric characterisation will be used to determine the influence of moisture content and degree of malt water binding on the dielectric properties, across the moisture content range (46-4\%) representative of typical malt kilning processes. The resulting electromagnetic energy penetration depths at different moisture contents, and the significance of this on applying dielectric heating to industrial scale kilning of malt will be considered in relation to validated empirical models for microwave and radio frequency dielectric properties of other agri-materials. This knowledge will enhance our understanding to select an appropriate frequency for heating trials. The moisture content, alpha amylase and beta amylase activity over the process time will be characterised and referenced against process temperatures and untreated samples. Finally, the experimentally determined dielectric heating energy requirements and processing times to produce malt with commercially acceptable moisture contents and enzyme activity levels are evaluated in comparison to conventional kilning processes. 


\section{$2 \quad$ Materials and methods}

\subsection{Malt preparation methodology}

Samples (500g or $2 \mathrm{~kg}$ green raw barley) were malted in a Custom Lab Micromaltings $\mathrm{K}$ steep-germinator and kiln (Custom Laboratory Products, Keith, UK). Typical process parameters were as follows:

- Steeping: Barley was steeped at $16{ }^{\circ} \mathrm{C}$ using an automated program of alternating wet (immersed) and dry (drained/ surrounded by air) stands designed to reach a steep out moisture content of $46 \%$. A '3-wet' steep cycle was used with the following cycle times ( $43 \mathrm{~h}$ in total): $7 \mathrm{~h}$ Wet- $12 \mathrm{~h}$ Dry- $8 \mathrm{~h}$ Wet $-12 \mathrm{~h}$ Dry $-4 \mathrm{~h}$ Wet.

- Germination: samples were transferred to individual malting 'cages' and germinated at $16{ }^{\circ} \mathrm{C}$ for 4 days, with automatic turning of the sample cages set at 1 min every $10 \mathrm{~min}$.

- Kilning: The air on temperature cycle during drying was as follows: $55^{\circ} \mathrm{C}$ for $12 \mathrm{~h}, 65^{\circ} \mathrm{C}$ for $6 \mathrm{~h}, 85^{\circ} \mathrm{C}$ for $2 \mathrm{~h}$, $95^{\circ} \mathrm{C}$ for $2 \mathrm{~h}$.

The final kilning stage was altered to provide samples of varying moisture contents for dielectric characterisation and heating trials. It should be noted that when producing malt samples for dielectric characterisation, reliable generation of stable samples in the expected intermediate bound water region was not possible. Malt is known to be extremely hygroscopic (Hardwick 1994) and samples rapidly reabsorbed moisture from the air between partial kilning and dielectric characterisation. Therefore, only a single sample in this region ( 15\% moisture) was obtained.

\subsection{Moisture content and enzyme analysis methodology}

Moisture content is a key parameter in malt specifications. The higher the moisture, the lower the extract yield per tonne of delivered malt (O'Rourke 2002). A maximum moisture content of $6 \%$ is required for safe storage and good milling performance in downstream processing (O'Rourke 2002). The moisture content of malt samples used for dielectric property measurement and RF processing was measured by mass loss on drying (replicate $5 \mathrm{~g}$ sub-samples, $3 \mathrm{~h}, 105^{\circ} \mathrm{C}$ ), according to conditions specified by Analytica-EBC, Method 4.2 .

Malt samples were analysed to determine the activity of the two key diastase enzymes required to break down starch into maltose in subsequent brewing processes, alpha and beta amylase (O'Rourke 2002). Malt alpha amylase (dextrinising units, DU) was measured using the Ceralpha Megazyme kit and malt beta amylase was measured using the Betamyl-3 kit (each from Megazyme, Bray, Ireland) with results expressed in betamyl units (BU). Results are reported throughout on a dry weight basis (dwb). 


\subsection{Bulk dielectric characterisation methodology}

The interaction of materials with an electric field is described by the materials dielectric properties. These values quantify how effectively a material will heat in an electric field, and are therefore, essential for understanding the interactions and ultimately optimising the design and scale up of an electromagnetic heating process. The bulk dielectric permittivity, $\varepsilon^{*}$ is a measure of the polarizability of a material in an applied electric field, which is expressed in its complex form as:

$$
\varepsilon^{*}=\varepsilon^{\prime}-j \varepsilon^{\prime \prime}
$$

Where $\varepsilon^{\prime}$ is the dielectric constant (the ability of a material to store energy via polarisation), $\varepsilon^{\prime \prime}$ is the dielectric loss (the ability of a material to convert stored energy to heat) and $j$ is $\sqrt{ }-1$ (Metaxas and Meredith 1983).

The room temperature $\left(21 \pm 1^{\circ} \mathrm{C}\right)$ bulk dielectric properties at $2450 \mathrm{MHz}$ were determined using the waveguide transmission line method (Clarke et al. 2003). This method was chosen as it allowed measurements to be made on the bulk grain material, in the same form as during kilning, (Nelson and Trabelsi 2006). It was most representative to take measurements in bulk grain form as the use of finely milled powder (required for open ended coaxial probe or cavity perturbation measurements) can lead to changes in the location and binding of water at the subcellular and cellular level, altering the dielectric properties (Pethig and Kell 1987). Further theoretical background of these types of measurements can be found in Lu et al. (2009). The experimental setup consists of a computer and vector network analyser (VNA) (model Agilent 8753ES) connected to both ports of an open-ended rectangular waveguide (size WR430), with two coax-to-waveguide adapters. The system has a sample holder of approximately $500 \mathrm{~cm}^{3}$ volume, with a material holder of polyether ether ketone (PEEK). Before measurements were conducted, the system was calibrated using the Thru-Reflect-Line (TRL) method (Engen and Hoer 1979). After calibration, the malt samples were placed in the PEEK sample holder, ensuring complete filling to prevent air gaps at the top of the sample. The bulk densities of the measured samples were calculated from their masses and volumes $\left(0.56-0.65 \mathrm{~g} / \mathrm{cm}^{3}\right)$. The VNA connected to ports 1 and 2 of the waveguide cell was then used to measure the scattering parameters: transmission coefficients $\left(S_{21}\right.$ and $\left.S_{12}\right)$ and reflection coefficients $\left(S_{11}, S_{22}\right)$ of the malt between 2.30 and $2.50 \mathrm{GHz}$ (Weir 1974). Measurements were carried out on three separate samples in triplicate; each data point represents an average of 9 measurements. The Newton-Raphson iterative method (Venkatesh and Raghavan 2005) was used to extract the dielectric constant and dielectric loss from the measured scattering parameters. 


\subsection{Bulk dielectric modelling methodology}

Where techniques to measure bulk dielectric properties at radio frequencies are not available, previously developed models to estimate dielectric properties based on known influencing variables can be used (Kraszewski and Nelson 1989). To develop a composite model for cereal grain, Kraszewski and Nelson (1989) used over 300 experimentally determined values for dielectric properties of barley, corn, rye and wheat, at a range of densities and moisture contents were taken between 5 and $5000 \mathrm{MHz}$. Multiple linear regressions were used to obtain the following expressions (Kraszewski and Nelson 1989):

$$
\begin{aligned}
& \rho /\left(\sqrt{\varepsilon^{\prime}}-1\right)=0.0358+1.8904 M^{1 / 2}+1.8622 M^{-1} \log f \\
& \varepsilon^{\prime \prime} / \rho=0.145+0.00148 M^{2} \log f-0.004615 M^{2}+0.008044 M^{2} / \log f
\end{aligned}
$$

Where $\varepsilon^{\prime}$ is the dielectric constant, $\varepsilon^{\prime \prime}$ is the dielectric loss, $\rho$ is the bulk density $\left(\mathrm{g} / \mathrm{cm}^{3}\right), M$ is the moisture content $(\%), f$ is the frequency $(\mathrm{MHz})$.

These expressions have been proposed as a general model for all cereal grains between $8 \%$ and $26 \%$ moisture, at $24^{\circ} \mathrm{C}$ and between $5 \mathrm{MHz}$ and $5000 \mathrm{MHz}$. Evaluation of this model against measured values reported average accuracies of $5 \%$ for the dielectric constant and $10 \%$ for the loss factor.

\subsection{Penetration depth determination methodology}

When a wave propagates in a dielectric material, power absorption causes its amplitude to diminish (Meredith 1998). The field intensity and power fall exponentially with depth from the material's surface. The penetration depth of electromagnetic energy into a material is defined as the depth at which the power flux falls to $1 / \mathrm{e}(0.368)$ of its surface value:

$$
D_{p}=\frac{\lambda_{0}}{2 \pi \sqrt{\left(2 \varepsilon^{\prime}\right)}} \times \frac{1}{\sqrt{\left[\left\{1+\left(\frac{\varepsilon^{\prime \prime}}{\varepsilon^{\prime}}\right)^{2}\right\}^{0.5}-1\right]}}
$$

Where $D_{p}=$ penetration depth $(m) ; \lambda_{0}=$ free space wavelength of incident radiation $(m) ; \varepsilon^{\prime}=$ dielectric constant; $\varepsilon "=$ dielectric loss factor.

The penetration depth in a material is an indicator of the potential to achieve heating uniformity within that material when energy is applied from a single source. It should be noted that some heating occurs beyond the defined penetration depth, as the electric field has not reached zero until some point after the penetration depth. Penetration 
depth is proportional to wavelength; at higher frequencies surface heating is more likely whilst at low frequencies volumetric heating is more readily attained (Thostenson and Chou 1999).

\subsection{Dielectric processing methodology}

A 20kW Sairem $50 \Omega$ RF system, operating at $27.12 \mathrm{MHz}$ in batch mode was used for the RF kilning trials. The generator provides electromagnetic energy via coaxial line to an applicator, with an automatic impedance matching network. A schematic overview of the radio frequency treatment system is illustrated in Figure 1.

A pair of parallel plate metal electrodes forms the cavity, and for an unloaded cavity applies a uniform electric field when the system is in operation. The malt to be processed was placed in slotted plastic trays of dimensions $100 \times 300 \times 400 \mathrm{~mm}$. Each slotted tray sat inside a tray of identical dimensions with baffles fixed in the bottom. Air volumetric flow rate through the bed was controlled by a rotameter; air was forced upwards through the bed to provide an airflow regime equivalent to industrial malt kilning operations, with a superficial velocity of $0.35 \mathrm{~m} / \mathrm{s}$ per metre of bed depth. Airflow was matched in this way to account for the difference in pressure drop across a deep commercial-scale bed (e.g. 0.8-1.2 m) and the shallow $100 \mathrm{~mm}$ bed used experimentally.

Three fibre optic sensors (3x Neoptix T1 Temperature Probes with a Neoptix Reflex Signal Conditioner) were embedded in the malt sample at approximately 20,50 and $70 \mathrm{~mm}$ from the bed surface, and in different topographical locations, to allow the bulk temperature of the samples to be monitored during processing. It should be highlighted that temperatures measured and quoted are average bulk measurements; due to the selective heating of water within malt, it is likely that the water phase will be significantly higher in temperature at the molecular level. The lack of localised and reliable temperature measurement methods is an ongoing challenge in RF and microwave processing (Kappe 2013). Conventional metal thermocouples are not suitable for use in electromagnetic heating systems, fibre optic sensors only supply point measurements, whilst infra-red thermal imaging is a surface technique. As it was not technically feasible to use real infra-red thermal imaging of the malt bed within the RF system, multiple fibre optic sensors were utilised.

Before RF treatment, the impedance of the system and the load were matched using a vector network analyser; the electrode height was fixed at $10 \mathrm{~mm}$ above the sample (experimentally determined height for optimum matching of power into the malt, therefore minimising any reflections) and the load capacitance and self-inductance were adjusted until a match of $>30 \mathrm{~dB}$ at $27.12 \mathrm{MHz}$ had been achieved. During RF treatment, applied and reflected RF power were measured; the load capacitance and self-inductance were manually increased or decreased as required to maximise absorbed power (target $>90 \%$ applied RF power).

Radio frequency heating trials were conducted on partially kilned malt samples to determine the differences in specific power for moisture removal between dielectric heating and conventional kilning. Treatments were carried out 
using different RF energy inputs (cumulative dose) which were achieved by varying the treatment time. Air flow was kept constant for all tests, at $0.36 \mathrm{~m} / \mathrm{s}$ per metre bed depth, benchmarked against commercial kilning processes. Initial scoping tests were conducted to determine the range of RF powers that could be applied to the material (with fixed airflow and fixed bed depth) whilst maintaining an average bulk temperature of between 63 and $67^{\circ} \mathrm{C}$ required for enzyme preservation. Between 0.6 and $1.0 \mathrm{~kW} / \mathrm{kg}$ of feed was found to be the optimum range, with higher power per unit mass resulting in overheating of the material and lower failing to reach the target temperature range of $65 \pm 2^{\circ} \mathrm{C}$. For $5 \mathrm{~kg}$ batch sizes used in testing, this was achieved at applied powers of approximately 3 and $5 \mathrm{~kW}$.

\section{Dielectric characterisation results}

\subsection{Bulk microwave measurements}

For agri-materials such as malt, dielectric properties are largely dependent on the moisture content, as water is the dominant phase able to interact with the applied electric field. To generate dielectric property data representative of the entire malt kilning cycle, barley samples were prepared and partially kilned down to a range of final moisture contents between 2 and $45 \%$. The dielectric properties of the malt samples at $2450 \mathrm{MHz}$ and ambient conditions are plotted in Figure 2 for a bulk density of $0.62 \mathrm{~g} / \mathrm{cm}^{3}$. Error bars represent the total combined error (one standard deviation of 9 separate measurements and instrumental error).

Figure 2 illustrates an increase in both the dielectric constant and the dielectric loss of malt with increasing moisture content. As water is the dominant phase able to interact with the applied electric field, these trends are expected. The malt kilning process typically comprises three water removal stages; a free water stage (down to approximately $25 \%$ moisture), an intermediate stage (approximately $25-12 \%$ moisture) and a bound water stage below $12 \%$ moisture (Briggs et al. 1981). Electrically, free water is well described by the Debye dielectric model, and exhibits a single relaxation in the microwave region (Kaatze 1989). However, the dielectric properties of bound water are less well defined and depend on the degree of binding and the resulting rotational freedom of the water molecules (Henry et al. 2003). The dielectric data presented in Figure 2 correlates well with expected moisture states in the conventional kilning process. Above $25 \%$ moisture the dielectric loss factor increases rapidly and linearly with increasing moisture content, due to the dominance of free water and the polarizability of the dipoles within it. Below $12 \%$ moisture content, the dielectric loss suggest a non-linear response with increasing moisture content, as previously observed for similar agri-food materials (Serdyuk 2008), attributable to the dominance of water bound to the malt structure which has a low extent of polarizability. Similar trends are seen in the dielectric properties of hard red winter wheat as measured by Nelson (1976). The lower dielectric losses at $2450 \mathrm{MHz}$ in the bound water region below $12 \%$ moisture indicate that this is a critical moisture level $(\mathrm{CML})$ in the industrial drying of malt. Above the CML, free water followed by intermediately 
bound water will be most readily removed. Below the CML, the energy needed to reduce the moisture content is expected to increase significantly compared to the free and intermediate water stages, due to the increased binding of water to the structure of the malt (Bala 1983).

\subsection{Modelled microwave and radio frequency dielectric properties}

Figure 3 illustrates the moisture dependence of the dielectric constant and loss at $2450 \mathrm{MHz}$ predicted by Nelson's general model, at moisture contents of $8-26 \%$, a bulk density of $0.62 \mathrm{~g} / \mathrm{cm}^{3}$, alongside the previously shown bulk waveguide dielectric measurements. Minimum and maximum values for the model predicted data are based on Nelson's previously reported average accuracies (5\% for the dielectric constant and $10 \%$ for the loss factor).

Figure 3 indicates a good agreement ( $9 \%$ maximum difference between averages) between the model predicted bulk dielectric properties and the measured bulk dielectric properties with respect to moisture content, for the $8-26 \%$ validated range of the model. This range corresponds to the average intermediately bound moisture for the cereal grains measured for model development. Given that the measured data fits sufficiently with the previously developed model for a range of different grain types, the model can be applied to malt allowing estimation of the bulk dielectric properties of malt at radio frequencies. Figure 4 illustrates the moisture dependence of the dielectric constant and loss at $27 \mathrm{MHz}$ and $900 \mathrm{MHz}$ predicted by Nelson's general model, at a bulk density of $0.62 \mathrm{~g} / \mathrm{cm}^{3}$. Minimum and maximum values for the model predicted data are based on Nelson's previously reported average accuracies $(5 \%$ for dielectric constant and $10 \%$ for dielectric loss). Figure 4 indicates an overall increase in both dielectric constant and loss at $27 \mathrm{MHz}$ compared to the microwave frequencies of $900 \mathrm{MHz}$ and $2450 \mathrm{MHz}$.

\subsection{Penetration depth}

In the case of kilning of malt in deep fixed beds at industrial scales, penetration depth is significant, as even temperature and moisture removal are critical for ensuring final product consistency. Figure 5 shows the penetration depth of electromagnetic energy into the malt at 2450,900 and $27 \mathrm{MHz}$, calculated according to the equation in section 2.5, plotted as a function of moisture content. The values at $2450 \mathrm{MHz}$ are based on measured dielectric properties whilst those at 900 and $27 \mathrm{MHz}$ are based on the model estimated dielectric properties. $900 \mathrm{MHz}$ is included here as it represent the industrially utilised frequency band typically used for large scale high power microwave heating processes.

At $2450 \mathrm{MHz}$, the penetration depth remains relatively constant at less than $6 \mathrm{~cm}$ above approximately $25 \%$ moisture content. This is attributable to the large fraction of free water present within the material which absorbs the microwave power. Between 12 and $25 \%$ moisture content, the penetration depth shows a gradual increase attributable to the reduced power absorption of the intermediately bound water. Analogous behaviour is evident at both $900 \mathrm{MHz}$ 
and $27 \mathrm{MHz}$, with a rapid increase in penetration depth below $\sim 12 \%$ moisture content and a relatively consistent penetration depth above $\sim 30 \%$ moisture content. The penetration depths calculated at the industrially utilised microwave frequencies of 2450 and $900 \mathrm{MHz}$ represent a significant limitation in the application of microwave heating at the scales typically seen in commercial malt kilning processes. Typically kiln bed depths are in the order of 0.5-1 metre in height; given that the penetration depth of microwave energy at $900 \mathrm{MHz}$ only reaches this scale below $\sim 7 \%$ moisture microwave heating is not suited to batch processing at this scale, and would be more suitable for continuous processing. Whilst penetration depth challenges at microwave frequencies have been overcome by tumbling materials with the microwave field (Filly et al. 2014), this is likely to be impractical at commercial scale. Likewise, microwave systems with multiple energy feeds can be designed that increase the volume of material effectively treated (Mehdizadeh 2015); however, the penetration depths at radio frequencies are an order of magnitude greater (metres vs $\mathrm{cm}$ ) and this strongly indicates that radio frequency heating is most technically feasible for the dielectric kilning of malt at industrial scales.

\section{$4 \quad$ Radio frequency processing results}

In the conventional kilning process, a break point occurs at the boundary between free water and intermediate water drying. The highest energy intensity occurs post-break, where the air-on temperature is increased and the air velocity reduced, to force the removal of intermediate water, followed by the bound water (European Brewery Convention 2000). The application of dielectric heating for the removal of free water has not been demonstrated in the literature to provide any significant process benefits with regards to energy efficiency (Raghavan et al. 2005). Malt samples were therefore kilned down to moisture contents in the intermediate water range $(12-25 \%$ moisture) prior to radio frequency treatment, to focus testing on the most feasible stage for the application of selective RF heating to the kilning process.

Figure 6 illustrates a time-dose-power treatment dataset typical of those generated during the RF treatment of the partially kilned malt. Note that steps up in applied power are a function of RF generator internal control, resulting from a gradual decline in absorbed power. Further scoping tests were used to determine initial targets for drying treatment energies, based on thermodynamic requirements. It was found that a minimum of $2 x$ the thermodynamic theoretical energy was required for moisture removal, and so this was selected as an initial baseline energy input for RF treatments.

\subsection{The influence of temperature on moisture content and enzyme activity}

In the kilning of malt, controlled heating and drying is critical for ensuring a consistent product quality with respect to end user specifications. Figure 7 illustrates the effect of temperature on residual moisture content of the malt samples treated at 3 and $5 \mathrm{~kW}$, following energy inputs of $235 \mathrm{kWh} / \mathrm{t}$ feed ( $2 x$ thermodynamic theoretical energy required 
to remove free moisture), and the untreated feed sample. At equivalent product temperatures, very similar moisture contents are observed at both 3 and $5 \mathrm{~kW}$ indicating that moisture removal is driven by temperature at these treatment times. Temperatures rising to $90^{\circ} \mathrm{C}$ (after removal of moisture at lower temperatures) are required to reduce the malt moisture content below the $6 \%$ specification maximum limit at $5 \mathrm{~kW}$ applied power.

Figure 8 illustrates the effect of temperature on the alpha and beta amylase activity in the 3 and 5kW RF treated samples, following energy inputs of $235 \mathrm{kWh} / \mathrm{t}$ feed, and the untreated feed sample. A reduction in alpha amylase activity is evident at temperatures above $\sim 65^{\circ} \mathrm{C}$, whilst beta amylase activity begins to deteriorate above $55^{\circ} \mathrm{C}$. A summary of the standard deviations and coefficients of variation observed in bed temperature for the two sets of treatments are given in Table 1, together with the resulting standard deviations and coefficients of variation in moisture content, alpha amylase and beta amylase activity, based on triplicate analysis. Overall, these results suggest that for the airflow regime, moisture content range and frequency tested here, an RF specific power of $0.6 \mathrm{~kW} / \mathrm{kg}$ malt feed is suitable for maintaining average temperature of $65^{\circ} \mathrm{C}$ across the whole bed whilst minimising the reduction in alpha and beta amylase activity compared to the unprocessed feed.

\subsection{The influence of energy input on removal of intermediate and bound water phases}

A key consideration in the application of novel drying processes is the energy requirements compared to conventional processing. As previously discussed, the energy intensive stages of malt kilning occur in the removal of intermediate and bound water, both of which have different energy requirements. The relationship between RF energy dose and moisture content removal over both the intermediate and bound water phases is illustrated in Figure 9. Treatments were carried out at 3 and $5 \mathrm{~kW}\left(0.6\right.$ and $1 \mathrm{~kW} / \mathrm{kg}$ feed) at a target bulk temperature of $65^{\circ} \mathrm{C}$. Overall, there is a slight increase in the rate of moisture removal at $5 \mathrm{~kW}$ compared to $3 \mathrm{~kW}$, however the energy requirements are very similar at the end of the drying cycle, with $290 \mathrm{kWh} / \mathrm{t}$ required to remove $8.2 \%$ intermediate and bound moisture. The data suggests two different drying regions; the first is down to $11 \%$ moisture, where an RF energy input of 27 $\mathrm{kWh} / \mathrm{t} / \mathrm{mc} \%$ is required for the removal of intermediate water. The second region is below $11 \%$ moisture, where 63 $\mathrm{kWh} / \mathrm{t} / \mathrm{mc} \%$ is needed to remove bound water. These different energy requirements for intermediate and bound water agree strongly with the dielectric properties reported in Figure 2, which showed a reduction in dielectric loss below approximately $12 \%$ moisture content. This can be attributed to reduced dissipation of electromagnetic energy within the material in the bound water region compared to the intermediate region.

Both the temperature and duration of kilning processes are known to influence the activity of alpha and beta amylase in malt (Gebremariam et al. 2012). The relationship between RF treatment time and alpha and beta amylase 
activity during the removal of bound and free water are illustrated in Figure 10. Enzyme activity measurements indicated that alpha amylase activity increased in the first few minutes for both 3 and $5 \mathrm{~kW}$ treatments. This could be due to extension of the germination process as is often seen in conventional kilning, during which enzyme synthesis continues (Bathgate 1973). At RF processing times beyond 600s, there is a decrease in the alpha amylase activity. The activity of beta amylase decreases from the start of RF processing. It is significant to note that these trends follow those seen in conventional kilning processes, but at much accelerated timescales. Previous research has shown that kilning at lower temperatures in the early stages of the moisture removal process results in reduced enzyme degradation (Briggs et al. 1981). The differences in both alpha and beta amylase activity between $3 \mathrm{~kW}$ and $5 \mathrm{~kW}$ indicate a degree of localised heating. Given that water is the main polar phase, this localised heating is likely due to the selective heating of water, due to increased specific power. This localised heating is sufficient to induce temperatures high enough to increase the rate of enzyme denature, although it is not sufficient to increase the rate of moisture removal (Figure 9). This selective heating is underlined by the greater reduction in enzyme activity, particularly with regard to beta amylase, at $5 \mathrm{~kW}$ compared to $3 \mathrm{~kW}$, for equivalent treatment times.

Tests were conducted to minimise the deactivation of enzymes by reducing the bulk treatment temperature. Free beta amylase is known to denature rapidly at temperatures above $55^{\circ} \mathrm{C}$ (Muller 2000), so this was selected as a target. To achieve lower bulk temperatures without increasing airflow through the bed (to greater than conventional kilning operations), a reduction in power was required. A specific power of $0.133 \mathrm{~kW} / \mathrm{kg}$ was suitable for maintaining a bulk temperature of $55^{\circ} \mathrm{C}$, achieved at $1 \mathrm{~kW}$.

Figure 11 illustrates the relationship between energy input and moisture removal at a bulk temperature of $55^{\circ} \mathrm{C}$, at the final stage of the drying cycle. Here, all the remaining moisture is tightly bound to the malt structure, allowing for minimal dipole rotation and therefore, limited dielectric heating. As in previous treatments, $63 \mathrm{kWh} / \mathrm{t} / \mathrm{mc} \%$ is required for the removal of bound water. Given that this energy requirement is the same at $0.133,0.6$ and $1.0 \mathrm{~kW} / \mathrm{kg}$ feed, it is suggested that for the tested range, the removal of bound water is not a function of specific power.

Figure 12 illustrates the relationship between RF treatment time and enzyme activity at bulk temperatures of $55^{\circ} \mathrm{C}$. There is no significant change in alpha amylase, and minimal denaturing of beta amylase compared to treatments at $65^{\circ} \mathrm{C}$ for equivalent processing times. This may be partially due to beta amylase being predominantly in its bound form at lower moisture contents, leading to better stability at higher temperatures compared to free enzymes (Sopanen and Laurière 1989), however a reduction in temperature of the selectively heated phase is also likely to be a contributing factor.

Overall the data presented here suggest that from an energy efficiency perspective, electromagnetic heating does not offer any process benefits compared to conventional heating where low bulk temperatures are required. For a 
typical kilning process with intermediate water removal from $25-12 \%$ and bound water removal from $12 \%$ to say $6 \%$ for a lager malt, the RF energy requirements determined under these test conditions are approximately $730 \mathrm{kWh} / \mathrm{t}$. Given that this does not include the removal of $20 \%$ free water and that conventional processes use $\sim 800 \mathrm{kWh} / \mathrm{t}$ for the whole kilning cycle, there is no energy benefit to using RF heating on its own. RF drying of intermediate and bound water is only likely to be viable where higher bulk temperatures will not adversely affect the material use downstream, as shown by the increased moisture removal at $95^{\circ} \mathrm{C}$ in Figure 7, at the expense of enzyme denaturing in Figure 8 .

Given that RF processing has resulted in drying times that can be reduced from hours to minutes, a possible processing option not evaluated here would be the application of RF heating integrated alongside conventional heating, to improve mass transfer of water and increase overall kiln throughput or reduce kiln footprint (so called hybrid processing). In addition, the provision of air flows considerably higher than those used in current commercial kilning operations could be considered, to provide enhanced 'cooling' of the malt. This would allow higher RF powers and shorter treatments to be used to improve selectivity and mass transfer, at bulk temperatures low enough to preserve enzyme activity, leading to potential energy efficiency gains in the intermediate drying phase.

As well as investigating hybrid drying using conventional and RF heating, future studies should address the development of techniques to allow measurement of bulk dielectric properties with temperature at radio frequencies. This would also enable the development of models to estimate the dielectric properties of a much wider range of materials under different processing conditions, and the use of numerical modelling to optimise the next generation of RF heating processes. Further investigation of how the activity of key enzymes varies across a wider range of temperatures under conventional heating would also lead to improved understanding of the degree of localised and selective heating occurring in electromagnetic heating processes.

\section{Conclusions}

The viability of replacing conventional hot air drying with RF heating in the industrial kilning of malt is likely to be determined by:

- the ability to kiln malt down to commercially acceptable moisture contents

- preservation of enzymes at the activity levels required for subsequent brewing processes

- a demonstrated process benefit such as reduced time and/or energy consumption

With reference to these factors and the initial objectives of this work, the following conclusions can be drawn about the feasibility of using electromagnetic heating for the industrial kilning of malt: 
- Bulk dielectric properties measured at microwave and radio frequencies between $46 \%$ and $2 \%$ moisture content indicate reduced dielectric polarisation in the bound water region below the $12 \%$ critical moisture level, suggesting higher energy requirements for removal of water in this region.

- Calculated penetration depths of $<10 \mathrm{~cm}$ at microwave frequencies (2450 and $900 \mathrm{MHz}$ ) are challenging to implement for batch processing at the scales typically required in kilning, and would require the use of multiple power feeds and components to enhance treatment homogeneity. However RF energy at $27.12 \mathrm{MHz}$ is technically feasible at industrial scales, with penetration depths $>2 \mathrm{~m}$ across the whole moisture content range.

- The preservation of both alpha and beta amylase activity requires bulk temperatures in RF heating below $65 \pm 2{ }^{\circ} \mathrm{C}$. This results in RF energy requirements of $27 \mathrm{kWh} / \mathrm{t} / \mathrm{mc} \%$ for the removal of intermediate water and $63 \mathrm{kWh} / \mathrm{t} / \mathrm{mc} \%$ for bound water.

- For the tested range $(0.13$ to $1 \mathrm{~kW} / \mathrm{kg})$ the removal of bound water is not a function of specific power; the increase in selective heating of moisture in this range is significant enough to denature enzymes due to their thermal sensitivity but not sufficient to increase mass transfer rates and improve energy efficiency of moisture removal.

- Significantly reduced processing times are achievable compared to conventional kilning, reduced from hours to minutes, which could provide an opportunity to increase throughput and reduced kiln footprint if integrated with conventional kilning in a hybrid process.

- Lower energy treatments can be achieved at high bulk temperatures however this leads to significant denaturing of both alpha and beta amylase enzymes. Electromagnetic heating shows potential to be economically viable where higher bulk temperatures are not critical for downstream use of the material.

\section{Acknowledgements}

The authors would like to express their gratitude to Muntons PLC for sponsoring this work. 


\section{References}

Bala BK (1983) Deep bed drying of malt. Faculty of Science, Agriculture and Engineering Newcastle University.

Bathgate G (1973) biochemistry of malt kilning. Brewers digest. 48, 60-65.

Beddington J Food, energy, water and the climate: a perfect storm of global events. In: Lecture to Sustainable Development UK 09 Conference, 2009.

Betz F (2003) Managing technological innovation: competitive advantage from change. John Wiley \& Sons,

Briggs D, Hough J, Stevens R \& Young T (1981) Malting and Brewing Science: Malt and Sweet Wort, vol 1. Springer US,

Buttress A, Jones A \& Kingman S (2015) Microwave processing of cement and concrete materials - towards an industrial reality? Cement and Concrete Research. 68(0), 112123.

CarbonTrust (2011) Maltings Industrial Energy Efficiency. In: Industrial Energy Efficiency Accelerator. vol CTG053. $\mathrm{p}^{\wedge} \mathrm{pp}$.

Clarke RN, Gregory AP, Cannell D, Patrick M, Wylie S, Youngs I \& Hill G (2003) A Guide to the Characterisation of Dielectric Materials at RF and Microwave Frequencies. Institute of Measurement and Control

National Physical Laboratory,

DEFRA (2013) Industry agree stretching energy efficiency targets with government. Available at https://www.gov.uk/government/news/industry-agree-stretching-energy-efficiencytargets-with-government.

Engen GF \& Hoer CA (1979) Thru-reflect-line: An improved technique for calibrating the dual six-port automatic network analyzer. Microwave Theory and Techniques, IEEE Transactions on. 27(12), 987-993.

European Brewery Convention (2000) Malting Technology. Getränke-Fachverlag Hans Carl,

Filly A, Fernandez X, Minuti M, Visinoni F, Cravotto G \& Chemat F (2014) Solvent-free microwave extraction of essential oil from aromatic herbs: From laboratory to pilot and industrial scale. Food Chemistry. 150, 193-198.

Gebremariam MM, Zarnkow M \& Becker T (2012) Effect of Drying Temperature and Time on Alpha-Amylase, Beta-Amylase, Limit Dextrinase Activities and Dimethyl Sulphide Level of Teff (Eragrostis tef) Malt. Food and Bioprocess Technology. 6(12), 3462-3472.

Hardwick W (1994) Handbook of brewing. CRC Press,

Henry F, Gaudillat M, Costa LC \& Lakkis F (2003) Free and/or bound water by dielectric measurements. Food Chemistry. 82(1), 29-34.

Jones DA, Lelyveld TP, Mavrofidis SD, Kingman SW \& Miles NJ (2002) Microwave heating applications in environmental engineering-a review. Resources, Conservation and Recycling. 34(2), 75-90.

Kaatze U (1989) Complex permittivity of water as a function of frequency and temperature. Journal of Chemical and Engineering Data. 34(4), 371-374.

Kappe CO (2013) Microwave Effects in Organic Synthesis: Myth or Reality? Angewandte Chemie International Edition. 52(4), 1088-1094.

Kraszewski A \& Nelson S (1989) Composite model of the complex permittivity of cereal grain. Journal of Agricultural Engineering Research. 43, 211-219.

Kunze W, Wainwright T \& Mieth H (1999) Technology brewing and malting, vol 669. VIb Berlin,, Germany,

Lu Z, Lanagan M, Manias E \& Macdonald DD (2009) Two-port transmission line technique for dielectric property characterization of polymer electrolyte membranes. The Journal of Physical Chemistry B. 113(41), 13551-13559.

Mehdizadeh M (2015) Microwave/RF Applicators and Probes: for Material Heating, Sensing, and Plasma Generation. William Andrew,

Meredith RJ (1998) Engineers' Handbook of Industrial Microwave Heating. Institution of Electrical Engineers,

Metaxas Aa \& Meredith RJ (1983) Industrial microwave heating. 
Muller R (2000) A mathematical model of the formation of fermentable sugars from starch hydrolysis during high-temperature mashing. Enzyme and microbial technology. 27(3), 337-344.

Nelson S (2008) Dielectric properties of agricultural products and some applications. Research in Agricultural Engineering. 54(2), 104-112.

Nelson SO \& Stetson LE (1976) Frequency and moisture dependence of the dielectric properties of hard red winter wheat. Journal of Agricultural Engineering Research. 21(2), 181-192.

Nelson SO \& Trabelsi S (2006) Dielectric spectroscopy of wheat from $10 \mathrm{MHz}$ to $1.8 \mathrm{GHz}$. Measurement Science and Technology. 17(8), 2294.

O'Rourke T (2002) Malt specifications \& brewing performance. Brew Int. 2(10), 27-30.

Pethig R \& Kell DB (1987) The passive electrical properties of biological systems: their significance in physiology, biophysics and biotechnology. Physics in medicine and biology. 32(8), 933.

Raghavan G, Rennie T, Sunjka P, Orsat V, Phaphuangwittayakul W \& Terdtoon P (2005) Overview of new techniques for drying biological materials with emphasis on energy aspects. Brazilian Journal of Chemical Engineering. 22(2), 195-201.

Serdyuk VM (2008) Dielectric study of bound water in grain at radio and microwave frequencies. Progress In Electromagnetics Research. 84, 379-406.

Sopanen T \& Laurière C (1989) Release and activity of bound $\beta$-amylase in a germinating barley grain. Plant Physiology. 89(1), 244-249.

Tassou SA, Kolokotroni M, Gowreesunker B, Stojceska V, Azapagic A, Fryer P \& Bakalis S (2014) Energy demand and reduction opportunities in the UK food chain. Proceedings of the ICE-Energy. 167(3), 162-170.

Thostenson E \& Chou T-W (1999) Microwave processing: fundamentals and applications. Composites Part A: Applied Science and Manufacturing. 30(9), 1055-1071.

Trabelsi S, Kraszewski AW \& Nelson SO (2001) New calibration technique for microwave moisture sensors. Instrumentation and Measurement, IEEE Transactions on. 50(4), 877881.

Trabelsi S \& Nelson SO (2003) Free-space measurement of dielectric properties of cereal grain and oilseed at microwave frequencies. Measurement Science and Technology. 14(5), 589.

Trabelsi S \& Nelson SO (2006) Temperature-dependent behaviour of dielectric properties of bound water in grain at microwave frequencies. Measurement Science and Technology. $17(8), 2289$.

Trabelsi S \& Nelson SO (2007) Unified microwave moisture sensing technique for grain and seed. Measurement Science and Technology. 18(4), 997.

Venkatesh M \& Raghavan G (2005) An overview of dielectric properties measuring techniques. Canadian biosystems engineering. 47(7), 15-30.

Weir WB (1974) Automatic measurement of complex dielectric constant and permeability at microwave frequencies. Proceedings of the IEEE. 62(1), 33-36.

Whitehurst RJ \& Van Oort M (2010) Enzymes in food technology, vol 388. Wiley Online Library, 
Table 1 Summary of experimental errors and standard deviations for influence of power and bed temperature on moisture content and enzyme activity at $235 \mathrm{kWh} / \mathrm{t}$

\begin{tabular}{|c|c|c|c|c|c|}
\hline \multicolumn{2}{|c|}{ Standard Deviation } & $\begin{array}{c}\text { Temperature } \\
\left({ }^{\circ} \mathrm{C}\right)\end{array}$ & $\begin{array}{l}\text { Final Moisture } \\
\text { content (\%) }\end{array}$ & $\begin{array}{l}\text { Alpha amylase } \\
\text { (DU/g, dwb) }\end{array}$ & $\begin{array}{l}\text { Beta amylase } \\
\text { (BU/g, dwb) }\end{array}$ \\
\hline \multirow{2}{*}{$3 k W$} & SD & 8.0 & 1.6 & 5.1 & 4.1 \\
\hline & CV & 12.5 & 2.5 & 7.9 & 6.5 \\
\hline \multirow{2}{*}{$5 \mathrm{~kW}$} & SD & 13.6 & 2.1 & 12.7 & 7.1 \\
\hline & CV & 19.4 & 2.9 & 18.1 & 10.2 \\
\hline \multicolumn{2}{|c|}{ Experimental error } & \pm 0.2 & \pm 0.1 & \pm 0.1 & \pm 0.1 \\
\hline
\end{tabular}

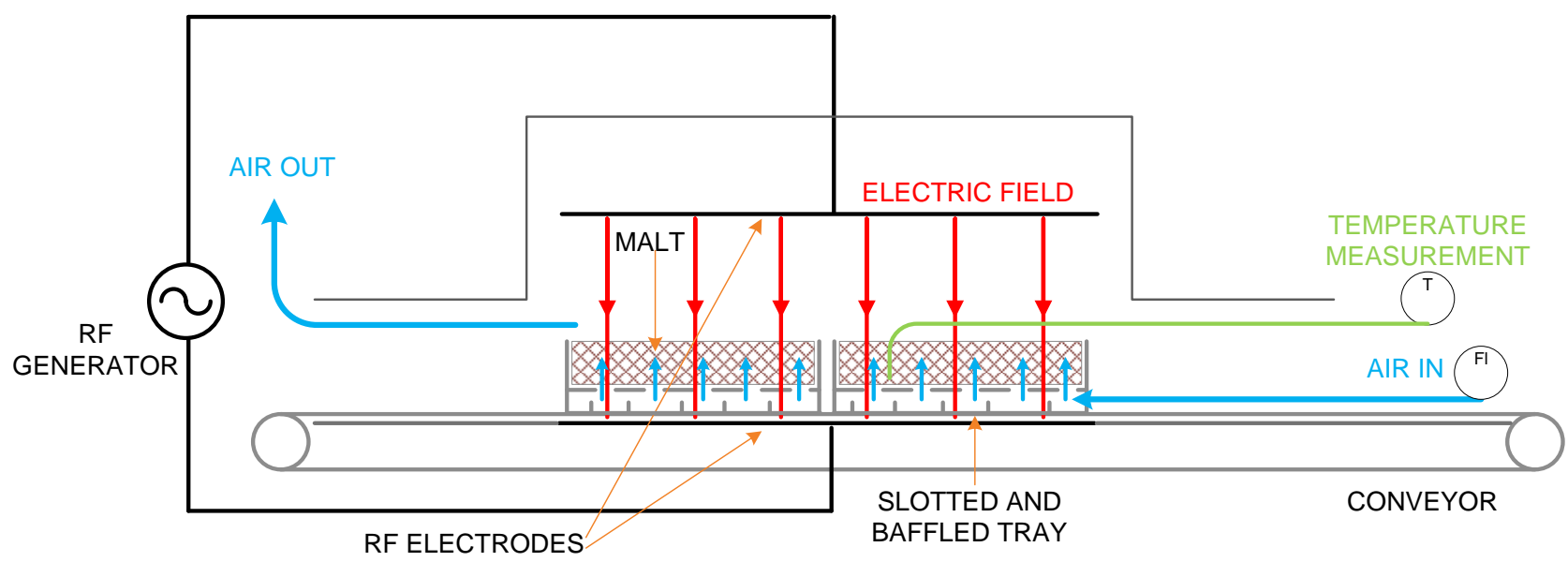

Figure 1 Radio frequency treatment system schematic 

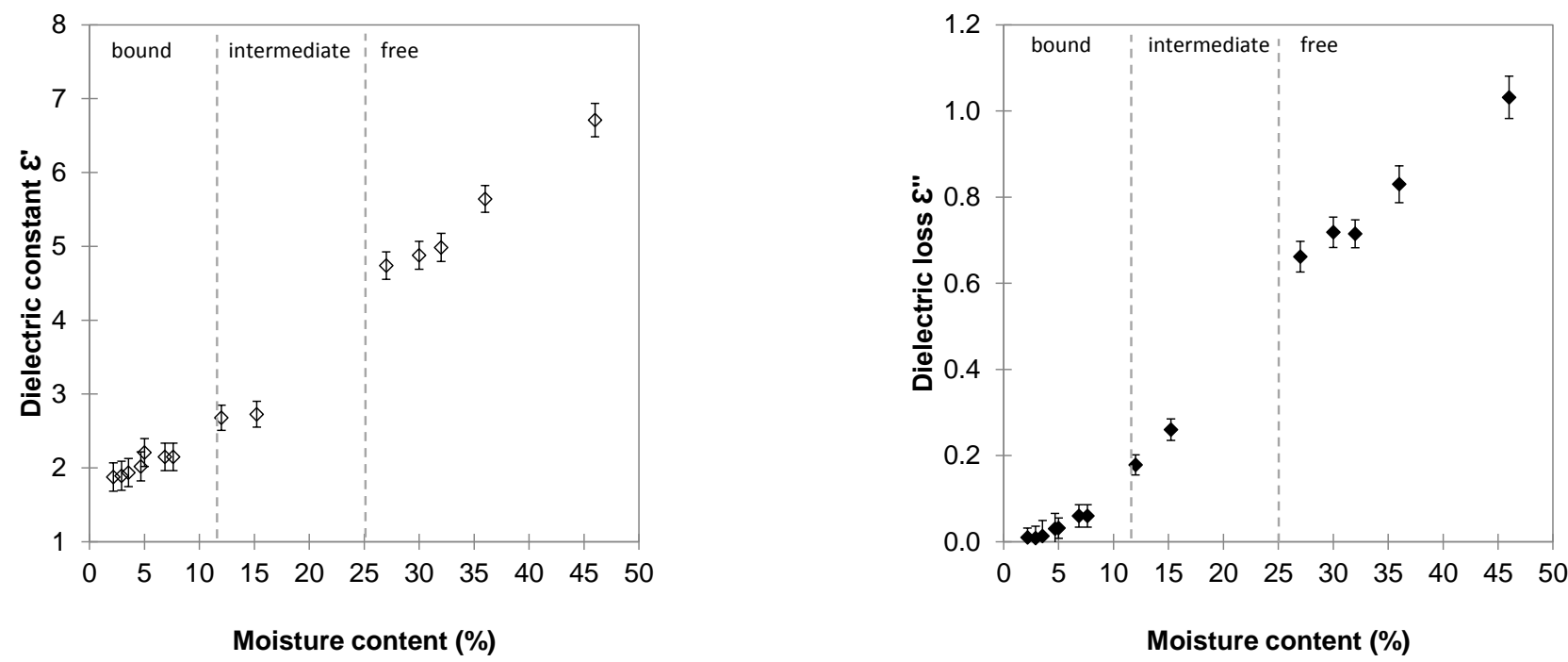

Figure 2 Average measured bulk dielectric constant and dielectric loss of malt, $2450 \mathrm{MHz}$, $20^{\circ} \mathrm{C}$, relative to industrial kilning drying stages

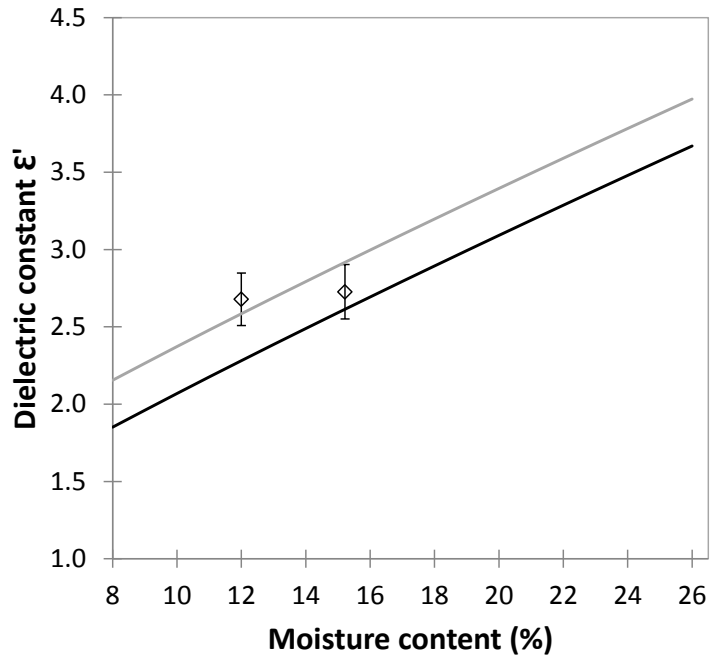

$\diamond 2450 \mathrm{MHz}$ (measured) $\quad 2450 \mathrm{MHz}(\mathrm{min})$

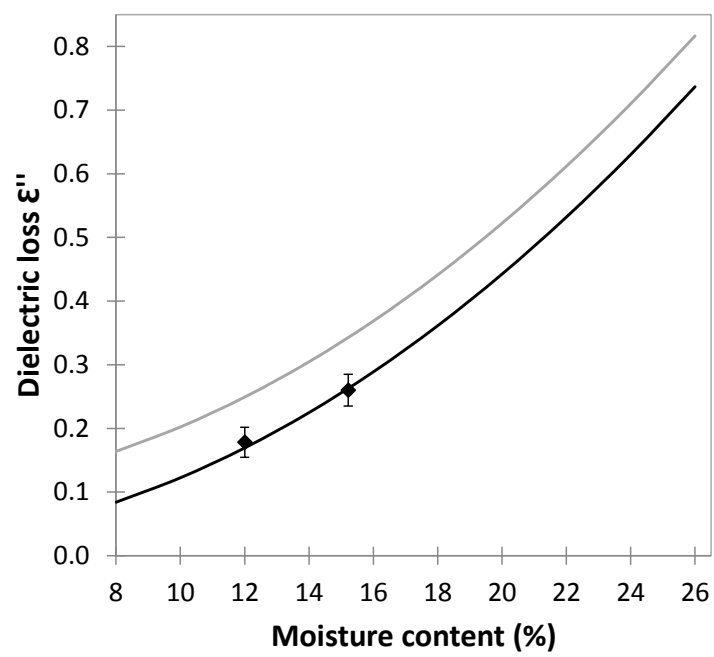

- $2450 \mathrm{MHz}$ (measured) $\quad 2450 \mathrm{MHz}(\mathrm{min})$

Figure 3 Benchmarking of experimental measurements against theoretical model for minimum and maximum bulk dielectric constant and dielectric loss of malt, $20^{\circ} \mathrm{C}, 2450 \mathrm{MHz}$ 


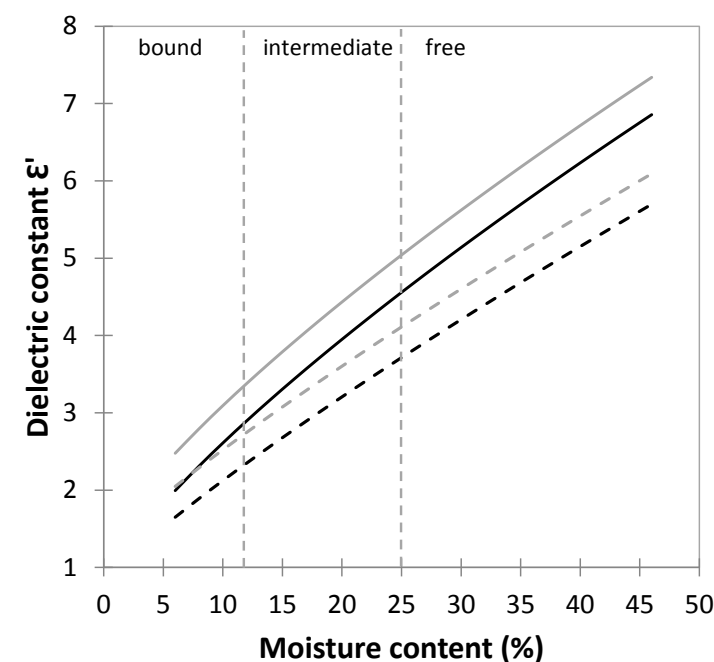

$27 \mathrm{MHz}(\min ) \longrightarrow 27 \mathrm{MHz}(\max )---900 \mathrm{MHz}(\min )---900 \mathrm{MHz}(\max )$

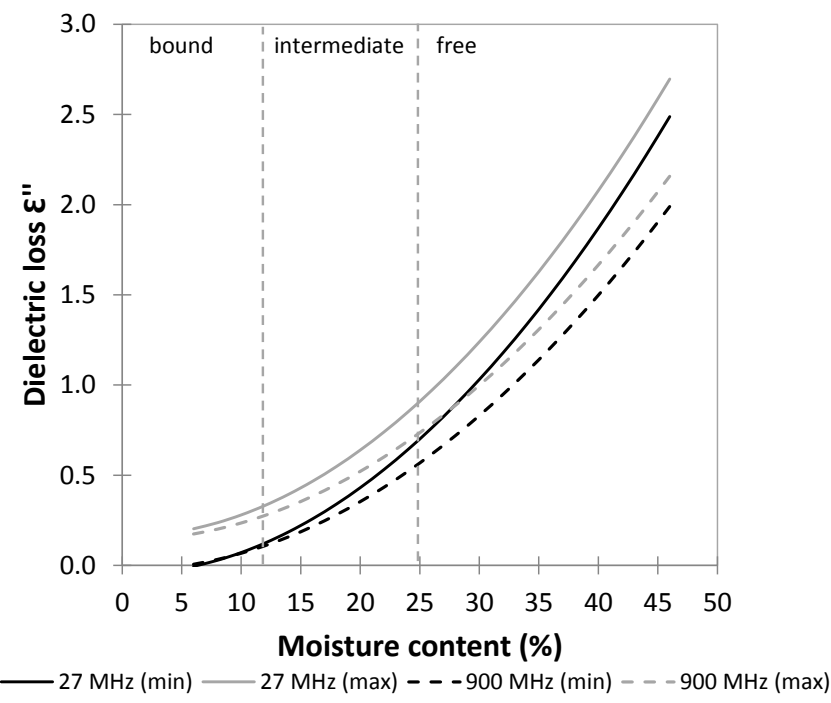

Figure 4 Predicted minimum and maximum bulk dielectric constant and dielectric loss of malt, $20^{\circ} \mathrm{C}, 27 \mathrm{MHz}$ and $900 \mathrm{MHz}$, validated model

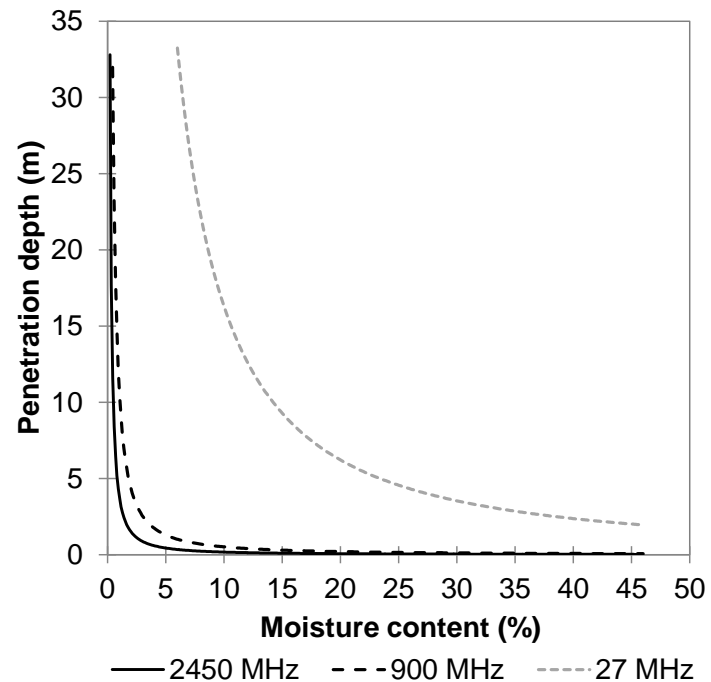

Figure 5 Penetration depth $(\mathrm{m})$ of electromagnetic energy into bulk malt, $20^{\circ} \mathrm{C}, 2450 \mathrm{MHz}$ (measured), $900 \mathrm{MHz}$ and $27 \mathrm{MHz}$ (predicted), $0.62 \mathrm{~g} / \mathrm{cm} 3$ 


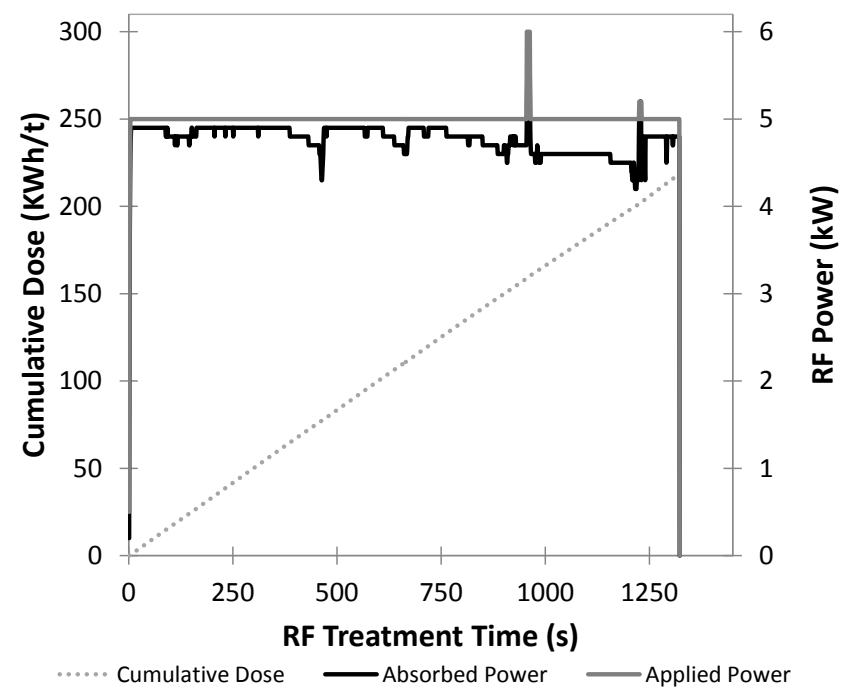

Figure 6 Example RF treatment time (s), applied (specific) power (kW), absorbed power $(\mathrm{kW})$ cumulative energy dose $(\mathrm{kWh} / \mathrm{t})$ for malt RF processing trials

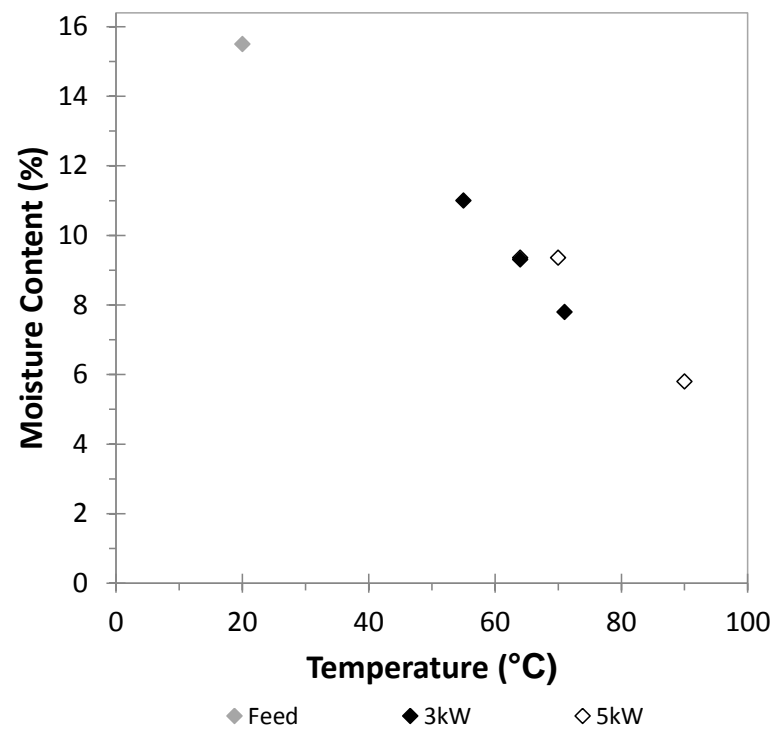

Figure 7 Effect of malt bed bulk temperature $\left({ }^{\circ} \mathrm{C}\right)$ on residual moisture content (\%) cumulative energy dose $235 \mathrm{kWh} / \mathrm{t}$ 

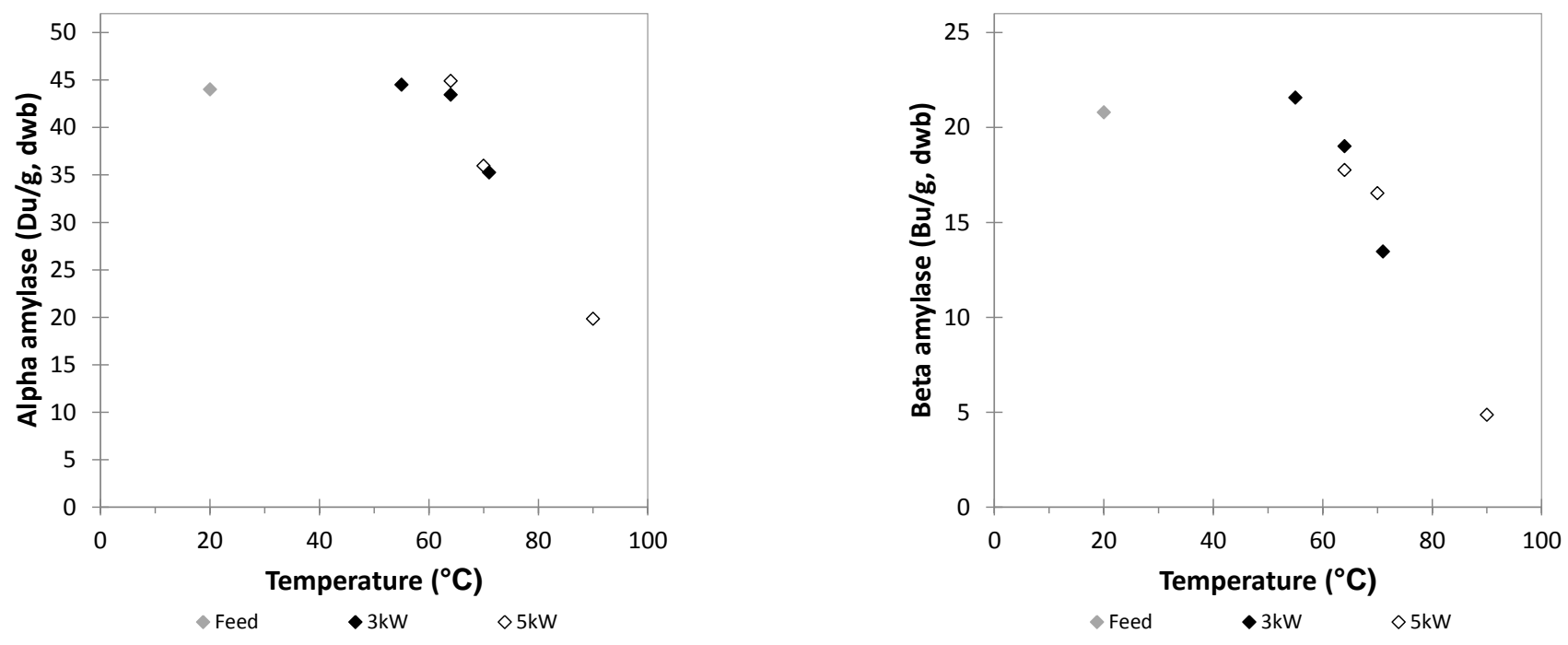

Figure 8 Effect of malt bed bulk temperature on enzyme activity, (DUdextrinising units, $\mathrm{BU}=$ betamyl units, dry weight basis), cumulative energy dose $235 \mathrm{kWh} / \mathrm{t}$
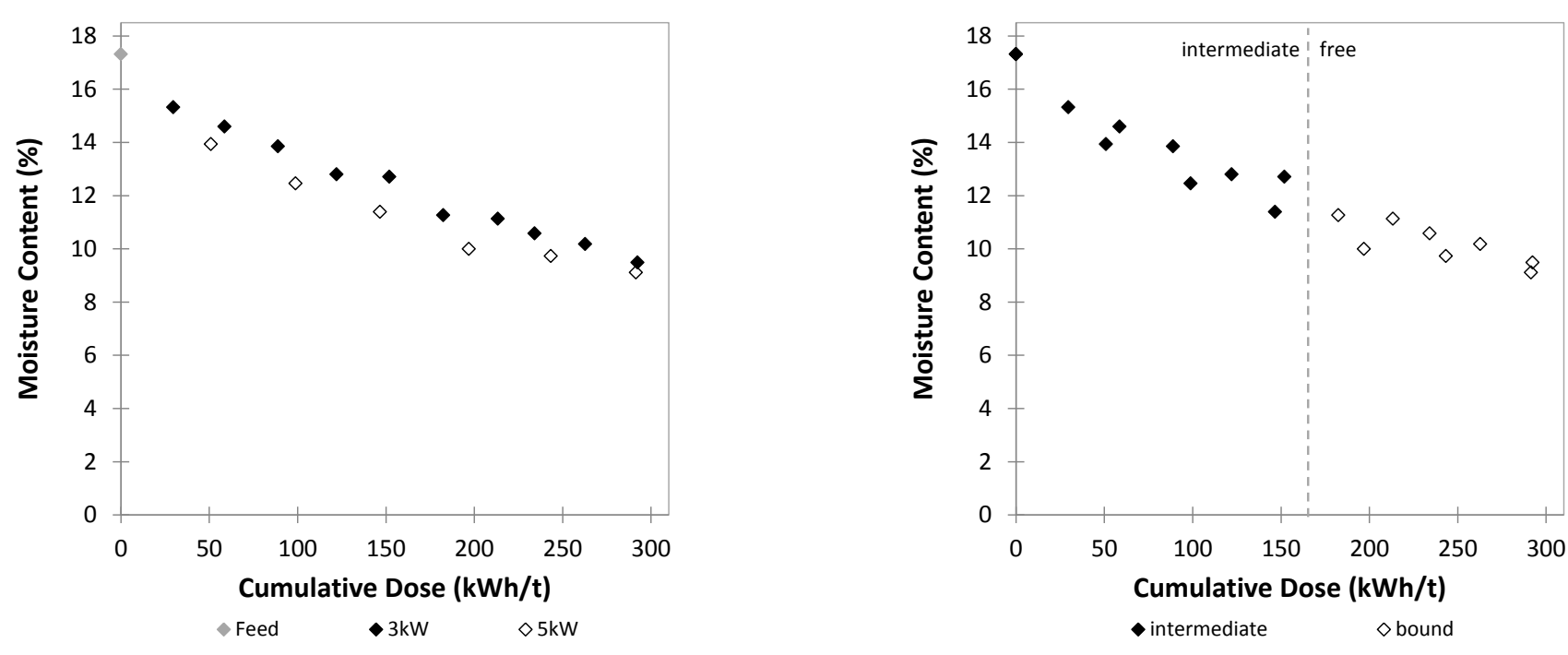

Figure 9 Effect of RF cumulative energy dose $(\mathrm{kWh} / \mathrm{t})$ on intermediate phase and bound phase moisture removal, $3 \mathrm{~kW}$ and $5 \mathrm{~kW}$ specific power, malt bed bulk temperature $65^{\circ} \mathrm{C}$ 

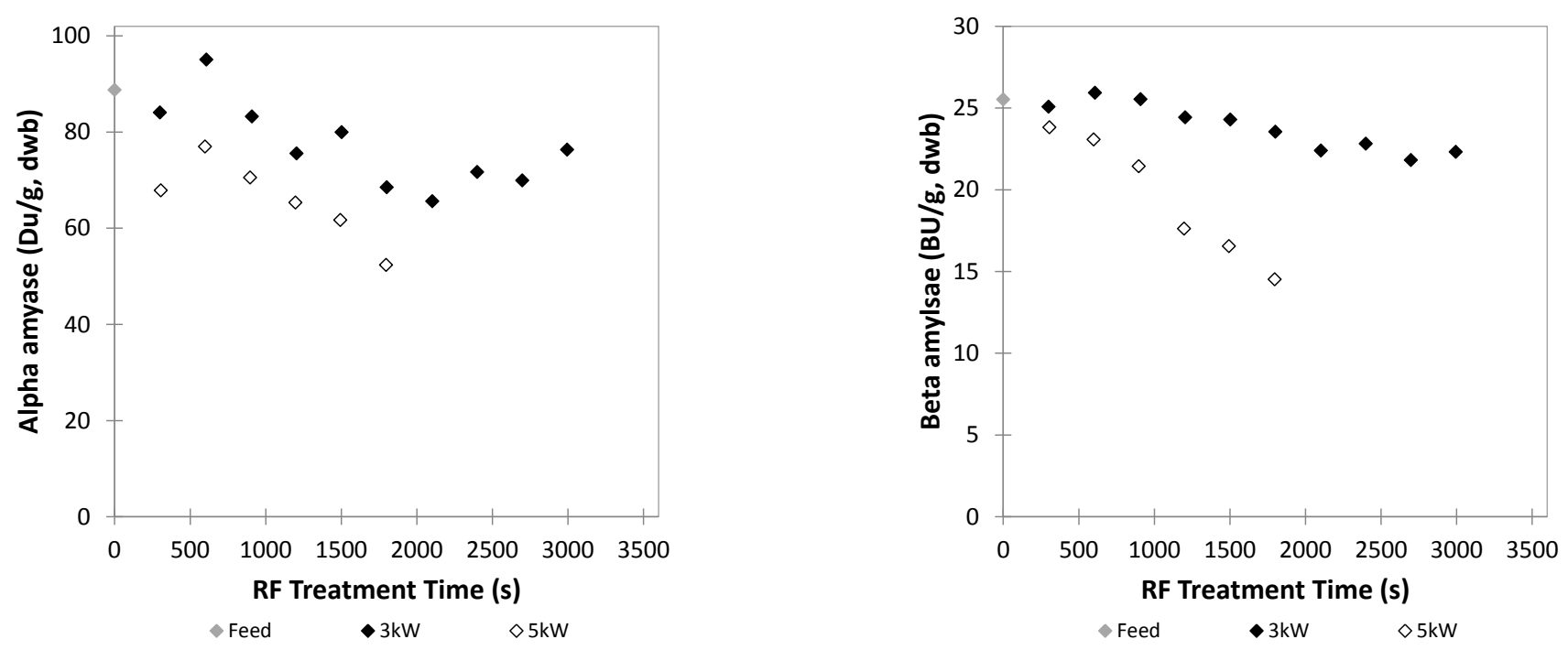

Figure 10 Effect of RF treatment time (s) and specific power (kW) on alpha amylase and beta amylase enzyme activity (DU-dextrinising units, BU=betamyl units, dry weight basis), malt bed bulk temperature $65^{\circ} \mathrm{C}$

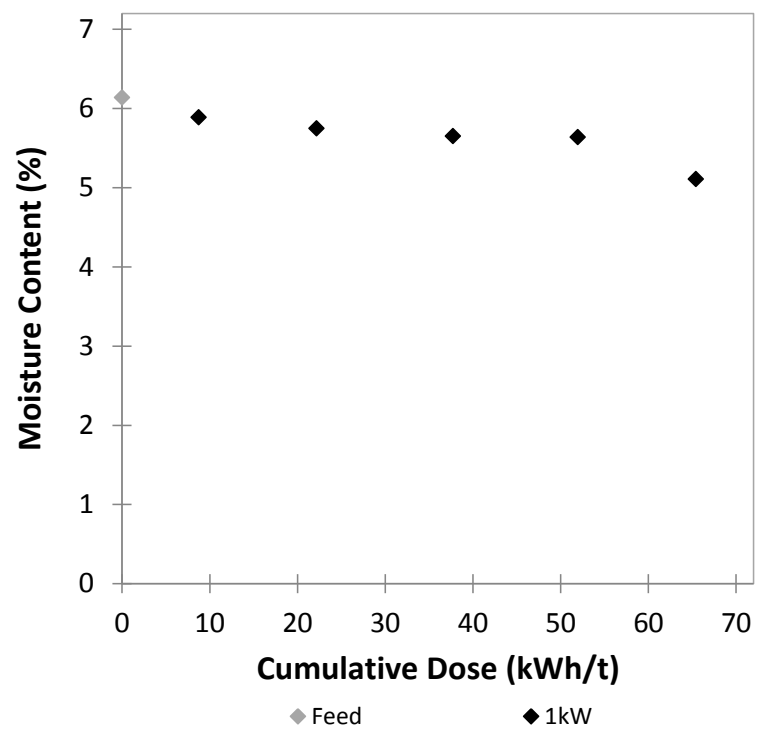

Figure 11 Effect of cumulative energy dose $(\mathrm{kWh} / \mathrm{t})$ on bound phase moisture removal, malt bed bulk temperature $55^{\circ} \mathrm{C}$ 

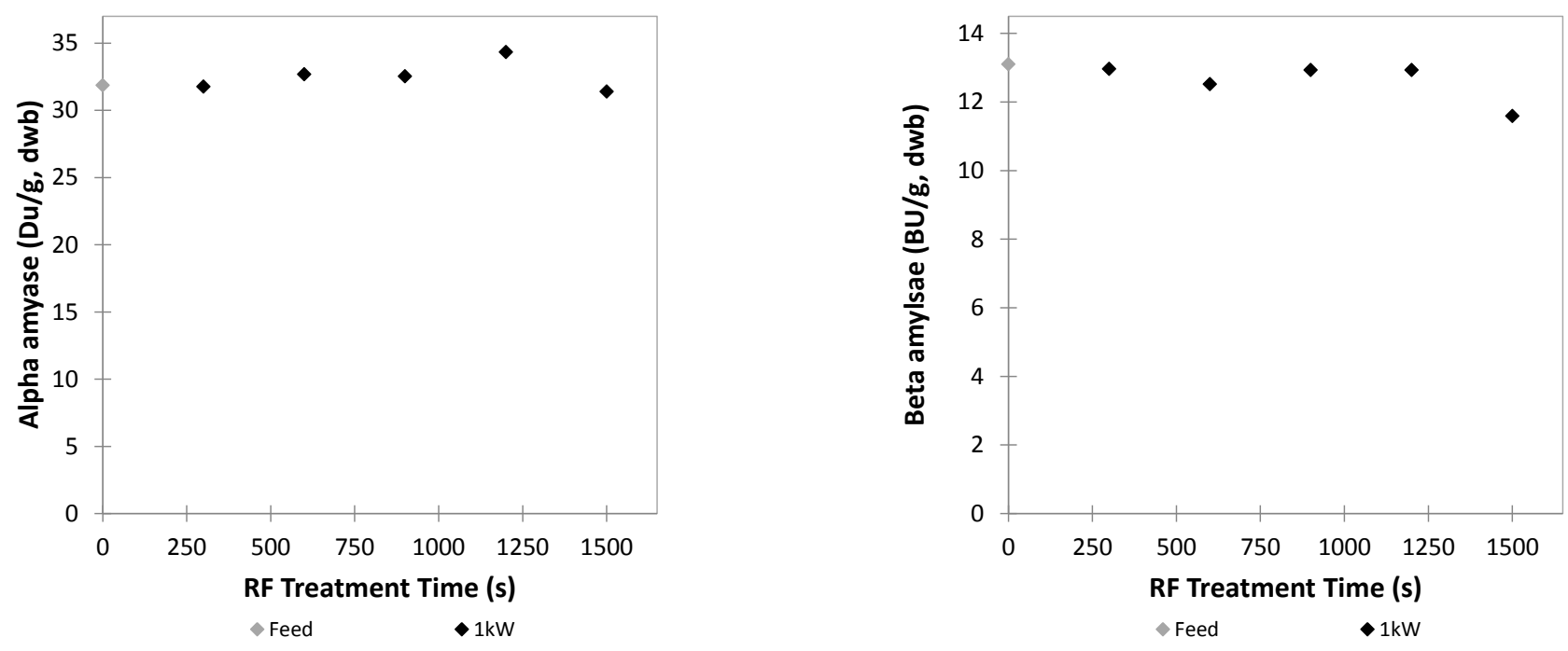

Figure 12 Effect of RF treatment time on alpha amylase and beta amylase enzyme activity, malt bed bulk temperature $55^{\circ} \mathrm{C}$, bound phase (DU-dextrinising units, $\mathrm{BU}=$ betamyl units, dry weight basis) 